\title{
Fluxgate: Tuned vs. Untuned Output
}

\author{
Pavel Ripka \\ Dept. of Measurement, Faculty of Electrical Engineering CTU, Technicka 2, 16627 Praha 6, Czech Republic \\ S.W. Billingsley, \\ Billingsley Magnetics, 2600 Brighton Dam Road, Brookeville, Maryland 20833, USA
}

\begin{abstract}
Fluxgate voltage output contains information about the measured DC magnetic field in amplitude of even harmonic components. Tuning the sensor output causes the concentration of output energy to specific harmonics (usually 2f) and parametric amplification. Short-circuited output current fluxgate cannot be tuned, but it in principle requires less turns of the pick-up coil. The noise measurements performed on amorphous ring-core sensors show no significant difference between current-output and tuned voltage-output, and higher noise level for untuned voltage-output.
\end{abstract}

Index Terms-Fluxgate magnetometer, magnetic field measurement, magnetic noise.

\section{INTRODUCTION}

Fluxgates are most precise magnetic field sensors in the $\mathrm{mT}$ to $\mathrm{nT}$ range. They are relatively complicated and power consuming, but they are capable of $\mathrm{nT}$ stability and $0.1 \mathrm{nT}$ resolution, which makes them remain attractive even though their principles of operation have been known since 1930s. What are the main disadvantages of their competitors [1]:

- Proton and Overhauser magnetometers are only scalar instruments, and they are even heavier and more power hungry: satellite Overhauser weights $1 \mathrm{~kg}$ and requires $3 \mathrm{~W}$ of power [2]

- High temperature SQUIDs have lower noise but require liquid Nitrogen

- Hall sensors are rather noisy and have temperature dependent offset

- Magnetodiodes and magnetotransistors work on interesting principles, but they do not perform better than Hall sensors of the same size

- GMI (Giant Magnetoimpedance and Giant

Magnetoinductance) effects are weak, and until recently, gave no practical sensor

- GMR (Giant magnetoresistors) have usually parabolic characteristics and 4\% hysteresis and nonlinearity [3]

- AMR (Anisotropic magnetoresistors) work well in the flipping mode [4], but have $>1 \mathrm{nT}$ noise

Manuscript received October 17, 1997

P. Ripka, +420 224352188 , fax +4202 3119929, ripka(afeld.cvut.cz, http://measure.feld.cvut.cz/usr/staff/ripka

W. Billingsley, +1 3017747707 , fax +13017740745

magnetic@iname.com, http://access.digex.net/ magnetic

This work was supported by the Grant Agency of the Czech Republic (\#102/96/1251)
The traditional fluxgate magnetometer processes the voltage induced in the pick-up coil, which may be tuned [5]. Another possibility is to use the short-circuited current; in such a case tuning is not possible. This paper compares the basic properties of the mentioned basic sensor modes: both untuned and tuned voltage output, and current output.

\section{INSTRUMENTATION}

The presented measurements were performed on a ringcore fluxgate sensor manufactured by Billingsley Magnetics. Similar sensors are used in low-power tri-axial magnetometers. The sensor core was wound on $17 \mathrm{~mm}$ diameter, bobbin made of anodized aluminum. The core consists of 3 wraps of $3 \mathrm{~mm}$ wide and $20 \mu \mathrm{m}$ thick tape of pre-annealed amorphous $2714 \mathrm{~A}$ alloy. The core was inserted into rectangular pick-up coil which was wound on fiberglass reinforced epoxy support. The pick-up coil length was always $15 \mathrm{~mm}$; the number of turns was 1500 for voltage output and 100 for current output. The sensor excitation coil had 220 turns of $0.2 \mathrm{~mm}$ diameter copper wire. The excitation circuit was $15 \mathrm{kHz}$ triangular current generator with adjustable amplitude which has low distortion. The excitation coil was tuned by variable parallel capacitor to increase the peaks of the excitation current. This technique proved to decrease the energy consumption of the excitation, lower the noise and suppress the perming effects (i.e. memory effect of the sensor core). Most of the measurements used a $0.6 \mu \mathrm{F}$ parallel capacitor and the excitation amplitude was 1.1 A p-p.

Sensor output was (after pre-amplification in case of untuned voltage, or current-to -voltage conversion in case of current output) connected to a DSP lock-in amplifier SR 830 (manufactured by Stanford Research Systems). The noise spectral density was measured on analog output of the lockin by using a SR 760 Spectrum Analyzer. The frequency range was $32 \mathrm{mHz}$ to $10 \mathrm{~Hz}$, spectrum was measured using BMH window as linear average of 50 , with $97 \%$ overlap. The sensor was inside a 5-layer permalloy shield (having a remanent field of about $1 \mathrm{nT}$ ) during the noise measurements.

All the measurements were performed in an open-loop, i.e. the measured field was not feedback compensated. 


\section{VOLTAGE-OUTPUT FLUXGATE}

\section{A. Untuned Voltage Output}

Fluxgate sensors can be considered induction coils with core permeability periodically changing with (excitation) frequency $f$. Untuned fluxgate voltage output contains information about the measured DC magnetic field in amplitude of even harmonic components $(2 \mathrm{f}, 4 \mathrm{f}, .$.$) , but the$ often used switching demodulator is sensitive only to $2 \mathrm{f}, 6 \mathrm{f}$. The waveform of the induced voltage often contains spikes from ringing at higher harmonics caused by parasitic capacitances. In our case, the capacitance of the pick-up coil was high and the zero-field output contained mostly 3rd harmonics (Fig. 1). The basic sensor sensitivity was 22

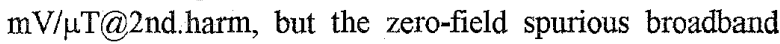
output voltage ("feedthrough") $V_{0}=2 \mathrm{~V}$ p-p caused overload of the lock-in input. The output voltage was therefore filtered with a low-noise active bandpass filter, tuned to 2 nd harm. frequency of $30 \mathrm{kHz}$, with gain $\mathrm{G}=20$. The resulting sensitivity was $400 \mathrm{mV} / \mu \mathrm{T}$, 2nd harmonic voltage amplitude at zero field was $\left|V_{20}\right|=32 \mathrm{mV}$, while the in-phase component corresponding to sensor offset was $\mathrm{V}_{20}=6.8 \mathrm{mV}$. The measured noise levels were 7 to $9 \mathrm{pTrms} / \sqrt{\mathrm{Hz}} @ 1 \mathrm{~Hz}$. Information contained in higher even harmonics was not used during this measurement.

\section{B. Tuned voltage output}

Tuning the sensor output causes the concentration of output energy to a specific harmonic (usually a $2 \mathrm{f}$ ) and parametric amplification. In some cases the basic circuit is unstable and it has to be stabilized by loading or damping. Stability study can be found in [6]. In our case, the value of the tuning capacitor was $1 \mathrm{nF}$ and the circuit was always stable. The sensitivity and null voltage were 220 $\mathrm{mV} / \mu \mathrm{T} @$ 2nd harm. and $\left|\mathrm{V}_{20}\right|=12 \mathrm{mV}$ respectively. The waveforms are shown in Fig. 2. The measured noise power spectral density was between 2.4 to $3.5 \mathrm{pTrms} / \sqrt{\mathrm{Hz}} @ 1 \mathrm{~Hz}$. Typical noise spectrum is shown in Fig. 3.

\section{CURRENT-OUTPUT FLUXGATE}

The short-circuited current output fluxgate [7] uses a current-to voltage converter and a gated integrator to process all even harmonic components. Unlike the voltage output, sensitivity of the current output is increasing for decreasing number of pick-up coil turns and strongly depends on coil geometry and resistance [8]. Individual harmonic components of current output are believed to have weak cross-correlation, which supports the necessity of using of a gated integrator instead of a synchronous detector. Our measurements were performed on a pick-up coil having $\mathrm{N}_{2}=$ 100 turns of $0.1 \mathrm{~mm}$ diameter wire. The current-to voltage converter was made using an LT 1028 opamp with a feedback resistor of $\mathrm{R}=1 \mathrm{k} \Omega$.

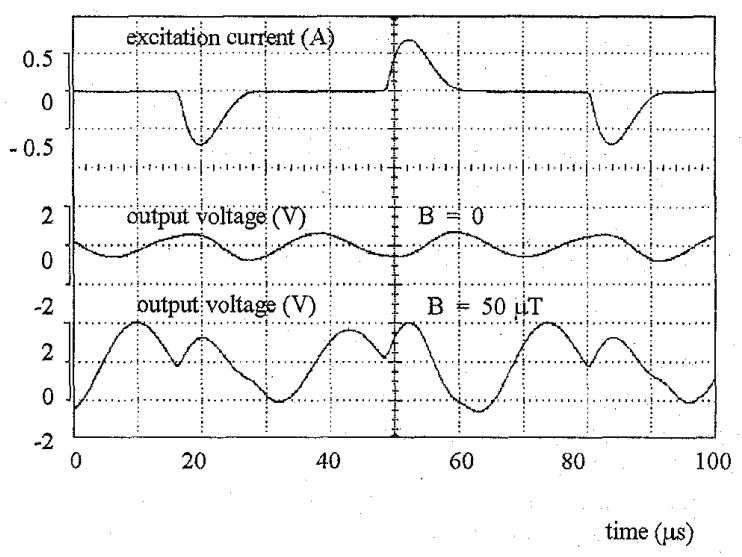

Fig. 1. Untuned voltage output fiuxgate: excitation current (upper trace), output voltage for measured field $B=0$ and $B=50 \mu \mathrm{T}$

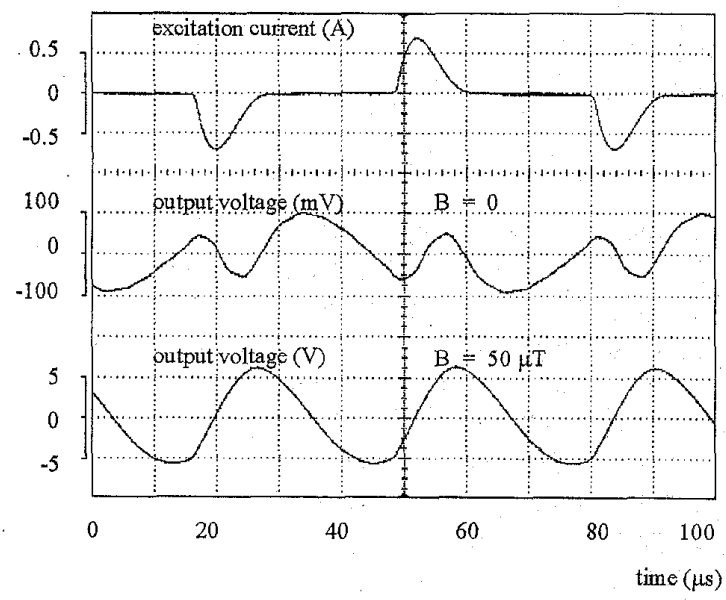

Fig. 2. Tuned fluxgate: same waveforms as in Fig. 1.
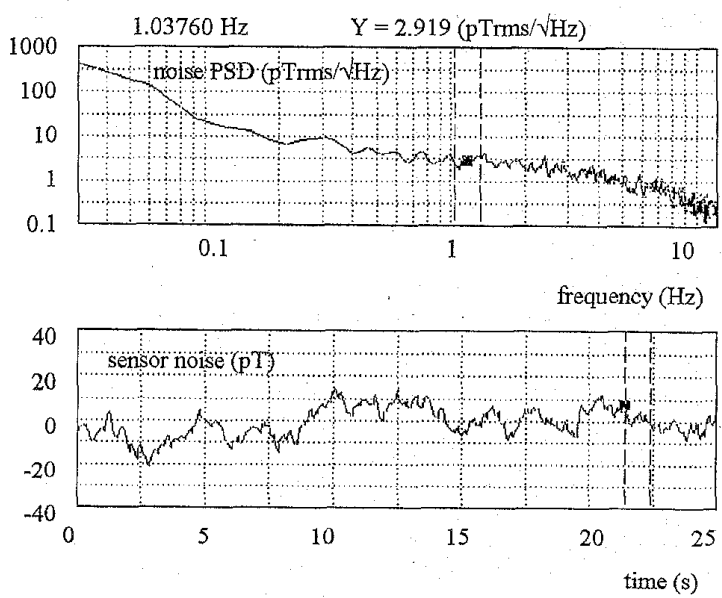

Fig. 3. Tuned fluxgate: Noise spectrum and time plot 
Fig. 4 shows the waveform of the excitation current and output current for measured field of $B=0$ and $B=50 \mu \mathrm{T}$. Fig. 5 shows the spectrum of the output current for $B=50$ $\mu \mathrm{T}$. The sensitivities and zero-field voltages measured by the lock-in amplifier at the I/ $\mathrm{V}$ converter output were:

$1.8 \mathrm{mV} / \mu \mathrm{T} @ 2 \mathrm{nd} \mathrm{h.,}\left|\mathrm{V}_{20}\right|=0.5 \mathrm{mV}, \mathrm{V}_{20}=0.4 \mathrm{mV}$

$0.7 \mathrm{mV} / \mu \mathrm{T} @ 4$ th h., $\left|\mathrm{V}_{40}\right|=0.8 \mathrm{mV}, \mathrm{V}_{40}=0.18 \mathrm{mV}$

The noise measured at the output of the lock-in amplifier tuned to the 2 nd harmonic (i.e. not using information contained in the higher even harmonics) was around $10 \mathrm{pT}$ $\mathrm{rms} / \sqrt{\mathrm{Hz}} @ 1 \mathrm{~Hz}$

The sensitivity can be increased either by increasing the feedback resistor or decreasing the number of turns of the pick-up coil. For $\mathrm{R}=12 \mathrm{k} \Omega$ the sensitivities and zero-field voltages were $25 \mathrm{mV} / \mu \mathrm{T} @ 2$ 2nd harm., $\left|\mathrm{V}_{20}\right|=8 \mathrm{mV}, \mathrm{V}_{20}=$ $7.8 \mathrm{mV}, 8.3 \mathrm{mV} / \mu \mathrm{T} @ 4$ th harm., $\left|\mathrm{V}_{40}\right|=12 \mathrm{mV}, \mathrm{V}_{40}=6$ $\mathrm{mV}$. The output signal was measured by a gated integrator with gating pulse length optimized for maximum sensitivity; this kind of detector is sensitive to all even harmonics. The

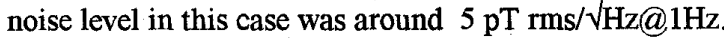

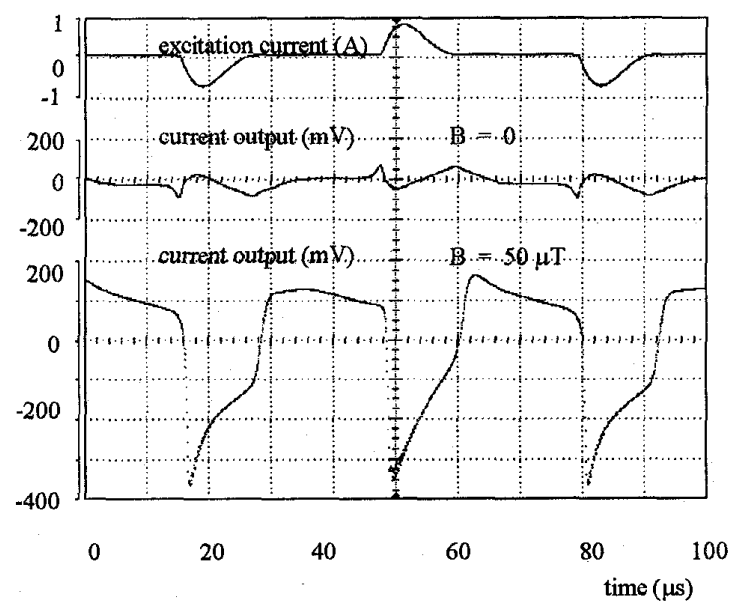

Fig. 4. excitation current (upper trace) and output voltage of the $\mathrm{I} / \mathrm{V}$ converter for $\mathrm{B}=0$ (middle trace) and $\mathrm{B}=50 \mu \mathrm{T}$ (lower trace). The converter constant was $1 \mathrm{~V} / 1 \mathrm{~mA}$.

The general problem of current-output fluxgate is the broadband feedthrough signal [9], which was in this case $V_{0}$ $=15 \mathrm{~V}$ p-p. The sensor used was not constructed for minimum feedthrough, which is believed to be a source of excessive noise.

\section{DISCUSSION AND CONCLUSIONS}

In contradiction to a previous study [10], the noise of tuned sensor (when using only 2nd harmonics) was significantly lower $(3.5+/-0.5 \mathrm{pTrms} / \sqrt{\mathrm{Hz}} @ 1 \mathrm{~Hz})$ than that of untuned one $(8+/-1$ pTrms $/ \sqrt{ } \mathrm{Hz} @ 1 \mathrm{~Hz})$. This is believed to be caused by the fact, that tuning the sensor output concentrates all the output power to 2nd harmonic

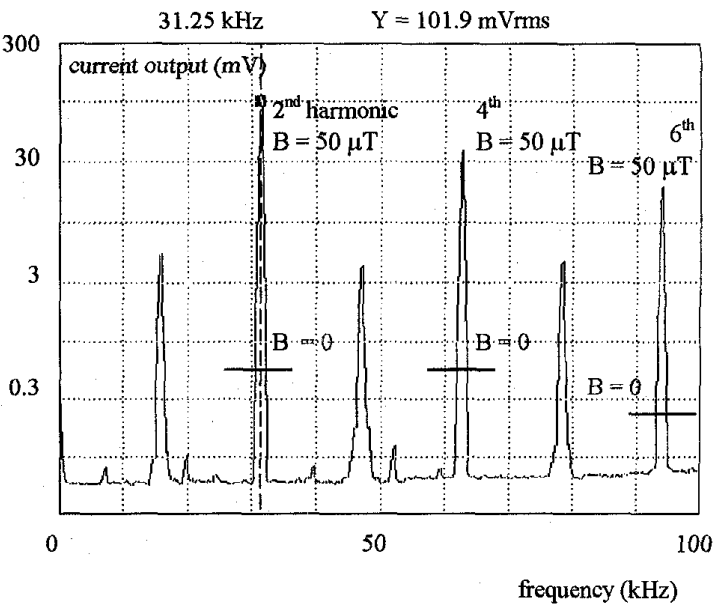

Fig. 5. Current output fluxgate: Spectrum of the output current, $1 \mathrm{~V} \cong 1 \mathrm{~mA}$. Measured for $\mathrm{B}=50 \mu \mathrm{T}$; levels for $\mathrm{B}=0$ are marked

frequency. The noise level of the second harmonic part of the the current output was also lower when using the output as processed by a gated integrator, which detects all even harmonics. The Current-output fluxgate requires a low number of pick-up coil turns. This may be an important advantage in case of an integrated fluxgate, where the micro-solenoids [11] or planar coils [12] are being used.

\section{REFERENCES}

[1] P. Ripka, "Noise and Stability of Magnetic Sensors," Journ. of Magnetism and Mag. Mat., Vol. 157, pp. 424-427, 1996.

[2] D. Duret et al, "Overhauser Magnetometer For the Danish Oersted Satelite," IEEE Trans. Magn., Vol. 32, pp. 4935 - 4937, 1996

[3] NVE data sheets, http://www.nve.com

[4] P. Ripka, "AC - excited magnetoresistive sensor," J. Appl. Phys., Vol. 8 , pp. 1-3, 1996

[5] Ripka: " Review of fluxgate sensors, "Sensors and Actuators A, Vol. 33, pp. 129-141, 1992

[6] Z. C. Gao, and R. D. Russel, "Fluxgate sensor theory," IEEE Trans. Geosci. and Rem. Sens., Vol. 25, pp. 862-870, 1987

[7] F. Primdahl, J. R. Petersen, C. Olin, K. Harbo Andersen, "The shortcircuited fluxgate output current, "J. Phys. E: Sci. Instrum., Vol. 22, pp. 349-353, 1989

[8] F. Primdahl, P. Ripka, J .R. Petersen, and O. V. Nielsen, "The ShortCircuited Fluxgate Sensitivity Parameters, "Meas. Sci. Technol., Vol. 2, pp. 1039-45, 1991.

[9] J. R. Petersen, F. Primdahl, B. Hernando, A. Fernandez, O. V. Nielsen, "The ring core fluxgate sensor null feed-through signal, "Meas. Sci. Technol., Vol. 3, pp. 1149-1154, 1992.

[10] F. Primdahl, and P.A. Jensen, "Noise in the tuned fluxgate," J. Phys. E. Sci. Instrum., Vol. 20, pp. 637-642, 1987.

[11] S. Kawahito, H. Satoh, M. Sutoh, and Y. Tadokoro: "High-resolution micro-fluxgate sensing elements using closely coupled coil structures," Sensors and Actuators A, Vol. 54, pp. 612-617, 1996

[12] B. Sauer, R. Gottfried, T. Haase and H. Kuck, "CMOS-compatible integration of thin ferromagnetic films," Sensors and. Actuators $A$, Vol. 42 , pp. $582-582,1994$ 